\title{
Annotation Guideline No. 6: SANTA 6 Collaborative Annotation as a Teaching Tool Between Theory and Practice
}

\author{
Matthias Bauer and Miriam Lahrsow
}

01.15 .20

Article DOI: $10.22148 / 001 c .11747$

Journal ISSN: 2371-4549

Cite: Matthias Bauer and Miriam Lahrsow, "Annotation Guideline No. 6: SANTA 6 Collaborative Annotation as a Teaching Tool Between Theory and Practice," Journal of Cultural Analytics. January 15, 2020. doi: 10.22148/001c.11747

\section{Preliminary Remarks}

These guidelines were developed in our seminar "Digital Methods in Literary Studies", which was aimed at M.A. students and advanced B.A. students. ${ }^{1}$ At the beginning of the seminar, students were introduced to the aims and challenges of digital annotating in general as well as to different narratological theories (including Genette, Ryan, Nelles, and Füredy). Due to its narratologically challenging nature, Mary Shelley's Frankenstein was chosen as a text against which we could test our guidelines and which triggered their modification. In Frankenstein many changes (e.g. of narrator and narratee) occur at the beginning of chapters. Even though such changes can, of course, also be found in the middle of chapters, annotators should pay special attention to the beginning of chapters, because they often coincide with a change in narrator, narratee, or narrated world.

\footnotetext{
${ }^{1}$ We would like to thank the organisers of SANTA and our anonymous reviewers for their detailed and valuable feedback. We would also like to thank our students Elisabeth Bleaß, Berit Boehling, Kristina Burghardt, Aylin El Damhougi, Leonie Greß, Yani Hu, Alia Luley, Günay Mammadova, Sandrina Kimberly Müller, Jona Odza, Yasemin Özalp, Laila Prota, Jonathan Schneider, Sarah Schneidewind, Andra Cristina Sterian, Lilien Sztudinka, Amina Tschubajew, Panagiotis Tzatsos, Ella Ujhelyi, Ningxi Xie, Yicong $\mathrm{Xu}$, and Karmen Zeiler for their great participation and input.
} 
One problem we debated in class was how to annotate in the first place: Should we only annotate the place in which the change occurs, e.g. the point between two different narrative levels, or should we annotate the whole passage belonging on one level? In the end, we decided to use a combined model, i.e. to allow both the use of paired brackets and the annotation of the point in-between two contrasting passages.

The in-class discussions soon drew our attention to fundamental problems that arise when trying to transform vague or even contradictory narratological theories into unambiguous, widely applicable annotation categories. The first issue was the definition of narrative itself. In particular, when does a dialogue, which is part of a narrative, become a narrative of its own? For example, is the statement "I went to the supermarket and bought some fruit" already a narrative? As a simple working definition we decided to chose "a report of connected events." ${ }^{2}$ This is important because, for example, Ryan has an even wider definition, ${ }^{3}$ which leads, as we think, to obscuring matters by a proliferation of narratives. The example, however, indicates a wider problem: there needs to be a clearly defined research question before starting to define and annotate narrative levels. For example, when one wants to find out whether novels from the eighteenth century tend to have more embedded narratives than twentieth-century novels, using annotation guidelines that are primarily based on Ryan's theory (see 1 and 4 below) might distort one's results because the crossing of an illocutionary or an ontological boundary does not necessarily establish an embedded narrative. Hence, even within the field of embedded narrative, there is no such thing as a 'universally marked-up text' that has to be annotated once and then can be re-used for many different research purposes.

The discussion of Frankenstein alerted us to another problem, namely the question of who, actually, is the narrator in a given passage: In the novel, Walton does not hear the Creature relate its own story; instead, it is filtered through Frankenstein. Who, then, is the narrator of the passages concerning the early life of the Creature? The Creature who related them to Victor, Victor who tells them to Walton (and maybe slightly manipulates them), or Walton who writes them down (and maybe does not transcribe Victor's tale verbatim)? For the sake of simplicity, we decided to go for the original source and assumed that the Creature is the most relevant narrator of its own tale. We also suggest to consider mediated documents (e.g. letters that are transcribed or read aloud by characters) as embedded narratives. The aspect of time (e.g. whether a certain part of

\footnotetext{
2"Narrative," Wikipedia, last modified September 22, 2018, https://en.wikipedia.org/wiki/Narrative.

${ }^{3}$ Marie-Laure Ryan, “Embedded Narratives and Tellability," Style 20 (1986): 319-40.
} 
the narrative occurs in a prolepsis) also had to be discarded since otherwise our guidelines would have become too complex. Furthermore, when contemplating how to annotate two narrative levels that describe different worlds, we decided not to use separate tags for dreams, beliefs, delusions, and the like. This would have led to a proliferation of tags and would have made annotation too dependent on the interpretation of the text (e.g. we sometimes cannot be sure whether a character is hallucinating/dreaming or not). Instead, according to our guidelines, annotators need only indicate whether the world depicted in the narration of a lower level is factually dependent on the world depicted in the higher level or not (see 4 below). We also agreed that it would be helpful to annotate whether a narrative on a lower level is embedded in, or framed by, the narrative of the higher level. (For the theoretical background see 5.1 below.) The problem was, again, one of drawing a clear line between framing and embedding. For example, when the narrated passage on the lower level is just as long as the narrated passage on the higher level, is the former embedded in, or framed by, the latter?

Hence, in our systematization of narrative levels we focused on the features that define narratives within narratives: the narrator (position) (see 2), the narratee (see 3 ) and the (in)dependence of the narrated world (see 4). We furthermore determined whether the narrative within a narrative is (quantitatively) the main narrative of the whole text or not and if its is fully enclosed (see 5). Last but not least, we took into account if the boundary between narrative levels is strictly observed or if there are cases in which, although we may notice a separate level of narration in some respects, the boundary is transcended in others (see 6).

A question that came up time and again during our discussions was which aspects our guidelines should cover in the first place. We might try to only annotate features that can be identified without much prior interpretation but this would mean to exclude exactly those issues that make literary analysis so intriguing. The students also wondered whether it is possible to develop guidelines that can be used for all literary texts. When we annotated the short texts provided by the organisers of SANTA, we soon realised that some of the phenomena that we included in our guidelines were not to be found in these texts, whereas some features that we identified in the texts were not covered by our guidelines. Hence, developing guidelines that are too specifically tailored to one text or genre will make the guidelines useless for analysing other texts, but when the guidelines are too general, they tend not to yield interesting results.

During our in-class discussions, it became clear to what extent annotation depends on definitions and interpretations. Students pointed out that, in the future, they would never rely to studies based on corpora without first considering the guidelines that were used to annotate them. Even though many of them were 
critical as to the applicability of annotation for their purposes as literary scholars, they appreciated the development and use of annotation guidelines as a tool for close reading: Rather than let an ambiguous text stay ambiguous, they simply had to decide for one option in order to be able to annotate a passage and had to justify their choice with reference to the whole text or to adapt the guidelines in order to address and document the ambiguity. Likewise, they had to precisely identify the location of changes (e.g. of level or narratee) in the text. Students also liked the idea of creating guidelines that were to be used by others as it provided a welcome contrast to writing term papers that no one but their lecturer would read. However, they would have appreciated to get the guidelines and annotated texts of all other participants and to receive feedback on their own guidelines (either by the organisers or by the participants who used them to annotate).

The biggest problem was that it was not really clear which research question the guidelines were designed to tackle. Depending on this, we could have shifted the focus of our guidelines by adding or omitting certain categories. Overall, our students enjoyed the SANTA competition because it enabled them to practice their close reading skills as well as to learn and critically evaluate a new method of conducting literary studies.

\section{Change of narrative levels (Genette)}

\section{Theoretical Explanation}

Change of narrative levels, ${ }^{4}$ a threshold between the one and the other: according to Genette, strictly speaking only a second narrative (metadiegetic level) within the first one (the intradiegetic one).

\section{1 an actual change of narrator}

an actual change of narrator (one of the narrated characters tells a story etc.); cf. Ryan's illocutionary boundary: a different speaker ${ }^{5}$

\section{2 no change of narrator}

no change of narrator

Definition of the three possible narrative levels:

1. Level within the global text at which the telling of the narrator-characters story occurs

2. The Level at which the primary narrators discourse occurs

\footnotetext{
${ }^{4}$ Gérard Genette, Narrative Discourse, trans. Jane E. Lewin (Oxford: Blackwell, 1980).

${ }^{5}$ Ryan, "Embedded Narratives and Tellability."
} 
3. The Level outside of the narrative act situated outside the primary narrator's discourse

Categories, Attributes, Values

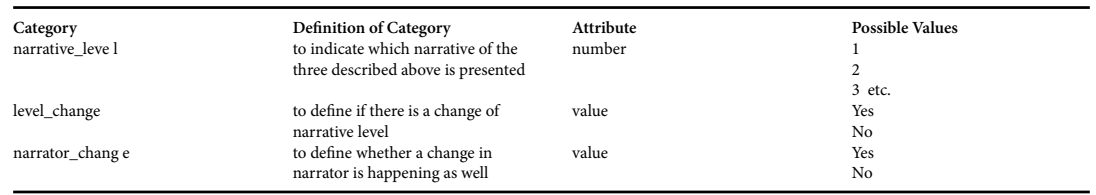

\section{Examples ${ }^{6}$}

\section{LEVEL CHANGE:}

[In the first sentence, the narrator is Walton, who is writing a letter to his sister. In the second sentence below, the narrator is the Creature, who is telling his story to Frankenstein, who, in turn, is telling it to Walton.]

$</$ level_change value=" "no" > So strange an accident has happened to us, that I cannot forbear recording it, although it is very probable that you will see me before these papers can come to your possession.

$[\ldots]$

$</$ level_change value $=$ "yes" $>$ It is with considerable difficulty that I remember the original æra of my being: all the events of that period appear confused and indistinct.

\section{NARRATIVE LEVELS:}

[In this example, we have Walton's narrative on Level 1, Frankenstein's embedded narrative on Level 2, and the Creatures' narrative, which is embedded in Frankenstein's, on Level 3.]

This manuscript will doubtless afford you the greatest pleasure: but to me, who know him, and who hear it from his own lips, with what interest and sympathy shall I read it in some future day! $[\ldots]<$ /narrative level $><$ narrative_level number = "2" $>$ I am by birth a Genevese; and my family is one of the most distinguished of that republic. My ancestors had been for many years' counsellors and syndics; and my father had filled several public situations with honour and reputation. $[\ldots]</$ narrative_level $><$ narrative_level number $=$ "3" $>$ I lay on my straw, but I

\footnotetext{
${ }^{6}$ Unless otherwise indicated, all examples are drawn from Frankenstein. Invented examples are marked with inv. after the number of the example, e.g.: $(4, i n v$. $)<$ Invented example>.
} 
could not sleep. I thought of the occurrences of the day. What chiefly struck me was the gentle manners of these people; and I longed to join them, but dared not. $</$ narrative_level $>$

\section{NARRATOR CHANGE:}

[In this example, the sentence marks a change of narrator from Frankenstein to the Creature.]

$</$ narrator_change value= "yes" $>$ It is with considerable difficulty that I remember the original æra of my being: all the events of that period appear confused and indistinct.

[In this example, we have marked that the narrator stays the same in a new chapter.]

Chapter VIII

Thus spoke my prophetic soul, as, torn by remorse, horror, and despair, I beheld those I loved spend vain sorrows upon the graves of William and Justine, the first hapless victims of my unhallowed arts.

Chapter IX

$</$ narrator_change value="no" $>$ Nothing is more painful to the human mind, than, after the feelings have been worked up by a quick succession of events, the dead calmness of inaction and certainty which follows, and deprives the soul both of hope and fear.

\section{Narrator's Position and Part in the Narrative (Genette)}

\section{Theoretical Explanation ${ }^{7}$}

2.1 The narrator is either part of the narration or not, i.e. s/he is:

2.1.1 Heterodiegetic narrator

2.1.2 Homodiegetic narrator

2.1.2.1 Autodiegetic narrator (special case of 2.1.2)

2.2 Narrator can also be identified according to their position with respect to the narrative levels:

\subsubsection{Extradiegetic narrator}

\subsubsection{Intradiegetic narrator}

\footnotetext{
${ }^{7}$ Gérard Genette, Narrative Discourse.
} 


\subsection{Narrator Participation}

2.3.1 Homodiegetic Narrator: The Narrator is part of the actual narration

2.3.2 Heterodiegetic Narrator: The narrator is not part of the actual narration

2.3.3 Autodiegetic Narrator: The narrator is part of the narration and is also the protagonist of the story

\subsection{Narrator Position}

2.4.1 Extradiegetic Narrator: Extradiegetic narrative level $=$ level at which intradiegetic events are described; literary act. An extradiegetic narrator does not appear as narrator within a diegesis.

2.4.2 Intradiegetic Narrator: Intradiegetic events are described within the first level of the narrative. There is also an intradiegetic narrator: s/he is already a character in a narrative that is not his/her own.

\section{Categories, Attributes, Values}

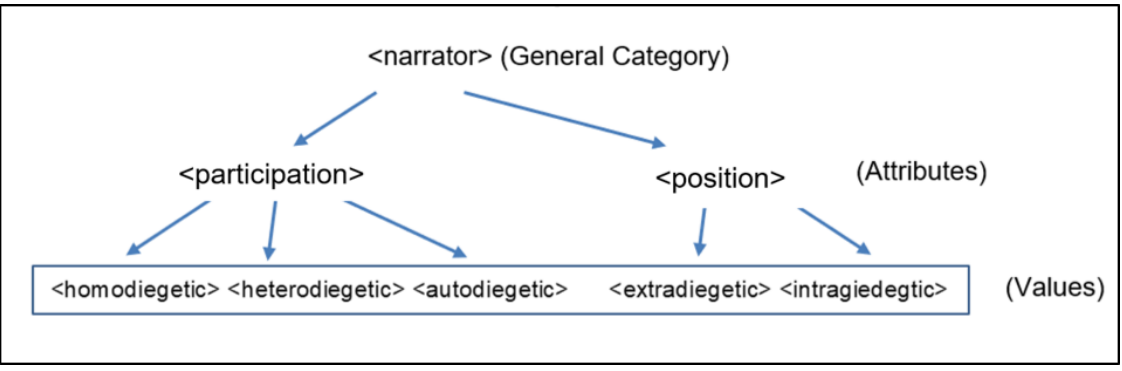

\section{Example}

(4) (Beginning of Chapter 7 of Frankenstein)

< narrator participation "homodiegetic narrator" > On my return, I found the following letter from my father: </narrator $>$

< narrator position "intradiegetic narrator" > "My dear Victor,

"You have probably waited impatiently for a letter to fix the date of your return to us; and I was at first tempted to write only a few lines, merely mentioning the day on which I should expect you. But that would be a cruel kindness, and I dare not do it. What would be your surprise, my son, when you expected a happy and glad welcome, to behold, on the contrary, tears and wretchedness? </narrator> 


\section{Narratee (Nelles)}

\section{Theoretical Explanation ${ }^{8}$}

We have included this category since sometimes narrative levels are only to be distinguished by a change of narratee. In other words, the narrator may remain the same, and the narrated world (see 4 below) may remain the same but the person to whom the story is told may become a different one. (E.g. when the autodiegetic narrator of the first-level narrative tells a story to a specific person within that narrative.)

\subsection{Change of narratee}

\subsection{No change of narratee}

Categories, Attributes, Values

\begin{tabular}{|c|c|c|}
\hline $\begin{array}{l}\text { Category } \\
\text { change_narratee }\end{array}$ & $\begin{array}{l}\text { Attribute } \\
\text { Value }\end{array}$ & $\begin{array}{l}\text { Possible Values } \\
\text { Yes/No }\end{array}$ \\
\hline
\end{tabular}

\section{Change of narrated worlds}

\section{Theoretical Explanation}

We have included this category since it is a key to providing significant information about the relation of the different narratives to each other: do they depend on each other or are they fictions within fictions? Just as fictional texts are counterfactually independent of the actual world, ${ }^{9}$ second-level narratives may be counterfactually independent of the world of the first-level narrative. Examples are inserted narratives (as in the Decamerone or the Canterbury Tales).

Ryan describes in her theory the crossing of boundaries, either illocutionary or ontological. An ontological crossing of boundaries refers to a change of reality. These kinds of reality shifts affect the narratological structure and are therefore important for our guidelines. A shift of reality occurs when narratives refer to two different worlds that are not dependent on each other.

Our category of narrated worlds is similar but not identical with Ryan's "ontological boundary," ${ }^{10}$ which is, however, not strictly logical and therefore impractica-

\footnotetext{
${ }^{8}$ William Nelles, Frameworks: Narrative Levels and Embedded Narrative (New York: Lang, 1997).

${ }^{9}$ Matthias Bauer and Sigrid Beck, "On the Meaning of Fictional Texts," in Approaches to Meaning: Composition, Values, and Interpretation, ed. Daniel Gutzmann, Jan Köpping and Cécile Meier (Leiden: Brill, 2014), 250-75.

${ }^{10}$ Ryan, "Embedded Narratives and Tellability."
} 
ble. In the case of narrated dreams it may sometimes be difficult to decide if there is a change of worlds, but even though in dream worlds different physical laws might apply, the dream world is dependent on the narrative world, either due to influence of the experiences of the dreamer or due to their prophetic character. This is why we recommend tagging dreams, as a rule, as "same world".

Categories, Attributes, Values

\begin{tabular}{lll}
\hline $\begin{array}{l}\text { Category } \\
\text { change_reality }\end{array}$ & $\begin{array}{l}\text { Attribute } \\
\text { value }\end{array}$ & $\begin{array}{l}\text { Possible Values } \\
\text { Yes } \\
\text { No }\end{array}$ \\
\hline
\end{tabular}

\section{Example}

[Even though both the narrator and the narratee change here, the narrated world does not change.]

(5) <narrative_level number="1"> This manuscript will doubtless afford you the greatest pleasure: but to me, who know him, and who hear it from his own lips, with what interest and sympathy shall I read it in some future day! $<$ /narrative level> $[\ldots]$

$\langle/$ change_narrator value="yes" $\rangle /$ change_narratee value="yes" $\rangle\langle/$ change_reality value="no" $>$

<narrative_level number "2"> I AM by birth a Genevese; and my family is one of the most distinguished of that republic. My ancestors had been for many years counsellors and syndics; and my father had filled several public situations with honour and reputation.

\section{The nature of the level-change structure}

\subsection{Embedding vs framing narrative}

\section{Theoretical Explanation}

1. Description of the theory: the initial idea of using this tag to mark a levelchange is framing of embedding. Embedding can be thought of as inserting or placing something within a larger unit, thus the main story is the embedding one. Framing is generally regarded as a presentational technique: the frame tale is of limited length and varying significance, serving to render the ampler inset or inner tale (Binnenerzählung) accessible 
and/or to authenticate it, imbuing it with a "narratorial illusionism," 11 particularly in simulations of oral storytelling, ${ }^{12}$ in which case the main story is the embedded one. However, there is no strict definition distinguishing how large a lower should be when it is called the embedding story, and similarly, how long a higher level should be when the lower level is called a framing story. Besides, if one identifies framing or embedding by finding which level the main story belongs to, the result could depend largely on interpretation.

Here, we provide an alternative by giving the number of words in each level which can be used to compare the length of levels without using the ambiguous term "framing" and "embedding".

2. Whenever there is a level change in the text, which should be tagged following the instruction in "(2) Change of narrative levels (Genette)", read the following guidelines to add the information of level length.

When counting the words of "level n", first count the number of words "Ln" between the tag <narrative_level number="n"> and the first end of tag $</$ narrative_level number=" $n$ " $>$ after it (so that you do not count any other parallel level $\mathrm{n}$ that does not belong to the same narrative).

If there is no "level $\mathrm{n}+1$ " within "level $\mathrm{n}$ ", $\mathrm{L}=\mathrm{Ln}$.

If there is "level $n+1$ " within "level n", count the number of words "Lma", "Lmb", "Lmc", etc. between each pair of beginning tag <narrative_level number=" $n+1$ " > and the its corresponding end tag $</$ narrative_level number=" $n+1$ " $>$ respectively. $\mathrm{Lm}=\mathrm{Lma}+\mathrm{Lmb}+\mathrm{Lmc} . . \mathrm{L}=\mathrm{L} n-\mathrm{Lm}$

Put the tag </narrative_level words="L" $>$ after the corresponding level tag $<$ narrative_level number="n" $>$

\section{Categories, Attributes, Values}

\begin{tabular}{lll}
\hline Category & Attribute & Possible values \\
Narrative_level & Words & [counted number of the words in Arabic letters] \\
\hline
\end{tabular}

\footnotetext{
${ }^{11}$ Ansgar Nünning, "On Metanarrative: Towards a Definition, a Typology and an Outline of the Functions of Metanarrative Commentary," in The Dynamics of Narrative Form: Studies in AngloAmerican Narratology, ed. John Pier (Berlin: de Gruyter, 2004), 11-57. 17.

${ }^{12}$ John Pier, "Narrative Levels," in The Living Handbook of Narratology, last revised October 10, 2016. http://www.lhn.uni-hamburg.de/article/narrative-levels-revised-version-uploaded-23april-2014.
} 


\section{Example}

(6, inv.) <narrative_level number="1" $><$ /narrative_level words="13"> Dear Mary, I had a conversation with a strange boy about frogs yesterday. $<$ narrative_level number"2" $><$ narrative_level words=" 6 " $>$ I have much interest in frogs. $</$ narrative_level number="2" $><$ /narrative_level number"1" $>$

\subsection{Opened vs closed narratives}

\section{Theoretical Explanation}

Both framing and embedding mentioned in 5.1 can have three kinds of structures concerning if they are complete: opened and closed, opened but never closed, and closed but never opened.

\section{Categories, Attributes, Values}

\begin{tabular}{lll}
\hline Category & Attribute & Possible Values \\
narrative_levelchang e & completion & Complete \\
& & Never closed \\
& Never opened \\
\hline
\end{tabular}

\section{When to use which value}

\subsection{1 opened and closed.}

When there is text between $<$ narrative_level number=" $n$ " $>$ and $<$ narrative_level number $=$ " $n+1$ " $>$, and there is text between $</$ narrative_level number=" $n+1$ " $>$ and $\langle/$ narrative_level number=" $n$ " $>$, the structure is opened and closed.

Put the tag </narrative_levelchange completion=" complete" $>$ before $<$ narrative_level number=" $n+1$ ">

\subsection{2 opened but never closed}

When there is text between $<$ narrative_level number= "n" $>$ and $<$ narrative_level number $=$ " $n+1$ " $>$, but there is no text between $</$ narrative_level number=" $n+1$ " $>$ and $</$ narrative_level number=" $n$ " $>$, the structure is opened and closed.

Put the tag </narrative_levelchange completion=" never closed" $>$ before $<$ narrative_level number="n+1" $>$

\subsection{3 closed but never opened}


When there is no text between $<$ narrative_level number=" $n$ " $>$ and $<$ narrative_level number $=$ " $n+1$ " $>$, but there is text between $\langle/$ narrative_level number=" $n+1$ " $>$ and $</$ narrative_level number=" $n$ " $\rangle$, the structure is closed but never opened.

Put the tag </narrative_levelchange completion=" never opened" $>$ after $</$ narrative_level number $=$ "n +1 " $>$

\section{Examples}

[In example 7, both the beginning and the end of the embedded narrative are marked and present in the text.]

(7) <narrative_level number="1"> Yesterday the stranger said to me, 'You may easily perceive, Captain Walton, that I have suffered great and unparalleled misfortunes.' $[\ldots]<$ /narrative_levelchange completion="complete" $><$ narrative_level number="2" $>$ I am by birth a Genevese; my family is one of the most distinguished of that public. [...] $<$ /narrative_level number="2" $>$ You have heard this strange and terrific story, Margaret; and do you not feel your blood congealed with horror, like that which even now curdles mine? $</$ narrative_level number "1" $>$

[In example 8, the switch from the frame narrative to the embedded narrative is included, but we never switch back to the frame narrative.]

$(8$, inv. $)<$ narrative_level number"1" $>$ Dear sister, I confronted a strange person yesterday and heard a thrill story from him. </narrative_levelchange complete="never closed" $><$ narrative_level number"2" $>$ I created a monster who has already killed several people. $<$ /narrative_level number" 2 " $><$ /narrative_level number"1">

[In example 9, the switch back from the embedded narrative to the frame narrative is included, but the text began with the embedded rather than the frame narrative.]

(9, inv.) <narrative_level number="1" $><$ narrative_level number=" 2 " $>$ A flying elephant is playing with a pink monkey. </narrative_level number"2" $>$ $</$ narrative_levelchengecomplete="never opened" $>$ Mom, I had an interesting dream last night. </narrative_level number="1"> 


\section{The nature of the boundary between the levels (Füredy)}

\section{Theoretical Explanation ${ }^{13}$}

This category is optional and should only be applied if there is at least one metalepsis (6.2) that can be clearly identified in a text.

\subsection{Strictly observed}

Strict boundary between narrative levels. (<boundary transgression="no" $>$ )

EXPLANATION: This category is applied when the boundary between narrative levels are respected. Strictly put: It is applied when a metalepsis (6.2) does not occur and therefore can not be applied.

\subsection{Metalepsis ${ }^{14}$}

EXPLANATION: A Metalepsis is identified according to Genette's terminology. Therefore, this category is only applied in instances were a transition between narrative levels can be identified and only if the following condition is fulfilled: Any intrusion by a narrator or narratee from outside of the particular narrative level that transgresses its internal logic. This can occur when an author (or his reader) introduces himself into the fictive action of the narrative, or when a character in a narrative intrudes into the narrative level of the author (or reader). Such intrusions disturb the distinction between levels.

6.3 Pseudo-diegetic narration (cf. Genette: second-level narrative told as firstlevel narrative $)^{15}$

"a narrative second in origin but which, lacking a diegetic relay, is narrated as though it were diegetic"16

\section{Categories, Attributes, Values}

\begin{tabular}{lll}
\hline Category & Attribute & Possible Values \\
Boundary & Transgression & No \\
& & Metalepsis \\
& & Pseudo \\
\hline
\end{tabular}

\footnotetext{
${ }^{13}$ Viveca Füredy, "A Structural Model of Phenomena with Embedding in Literature and Other Arts," Poetics Today 10 (1989): 745-69.

${ }^{14}$ Genette, Narrative Discourse.

${ }^{15}$ Genette, Narrative Discourse.

${ }^{16}$ Pier, "Narrative Levels."
} 


\section{Examples}

(10) <boundary transgression="no">this is a passage with a strict boundary. $</$ boundary $>$

(11) $<$ boundary transgression="metalepsis" $>$ this is the passage with the metalepsis. $<$ /boundary $>$

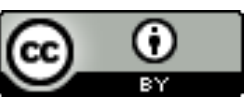

Unless otherwise specified, all work in this journal is licensed under a Creative Commons Attribution 4.0 International License. 